\author{
П. Н. Виноградов ${ }^{1}$, П. А. Яркин ${ }^{1}$ \\ 1 Российский государственный педагогический университет имени А. И. Герцена, \\ 191186, Россия, Санкт-Петербург, наб. реки Мойки, 48
}

\section{Сведения об авторах:}

Виноградов Павел Николаевич

e-mail: palvin@mail.ru

ResearcherID: E-9964-2017

ORCID: 0000-0003-0012-7813

SPIN-код РИНЦ: 6143-3151

\section{Яркин Петр Алексеевич}

e-mail: petr.yarkin@gmail.com

ResearcerID: D-7094-2017

ORCID: 0000-0001-6722-2474

SPIN-код РИНЦ: 9242-7352

\section{Финансирование:}

Исследование выполнено при поддержке Российского фонда фундаментальных исследований, проект № 19-013-00835.

\section{(C) Авторы (2019). \\ Опубликовано Российским государственным педагогическим университетом им. А. И. Герцена.}

Аннотация. В процессе взаимодействия с природными объектами человек реализует определённую тактику поведения. Эта активность регулируется системой представлений и ценностей, осознаваемых им в разной степени. Предметом исследования являются ценностные основания этического выбора, выраженные в языковом описании экологических проблем, осознаваемых человеком при взаимодействии с природными объектами. Испытуемым предложено написать экологические эссе. Текст, объясняющий выбор, проявляет особенности использованного дискурса. Для анализа текста использованы методы дистрибутивной семантики. Такой подход позволяет построить классификацию оснований для этического экологического выбора и конструировать образовательные материалы, соответствующе особенностям обучающихся разных категорий. В статье раскрывается один из методических приемов исследования коллективного экологического сознания, в основу которого положен анализ текстов, порождаемых обучающимися. Тексты эссе на заданную тему анализируются с точки зрения частоты использования тех или иных слов. Для проверки наших предположений были проанализированы эссе студентов на тему «Что может позволить себе человек в отношениях с природой». Произведен анализ облака слов, с помощью которого можно охарактеризовать экологический дискурс, а на его основе описать содержание экологического сознания. Данный корпус текстов отражает коллективные особенности экологического сознания и социальные представления студентов, обучающихся по различным направлениям и специальностям. Здесь под социальными представлениями мы понимаем форму знания, являющуюся продуктом коллективного творчества и имеющую практическую направленность, позволяющую создать общую для некоторой социальной группы реальность. Анализ проводился в среде R version: 3.5.1 с использованием пакета Quanteda version: 1.4.3. Создание скрипта на языке $\mathrm{R}$ позволяет автоматизировать обработку и повторять анализ на других корпусах текстов.

Ключевые слова: коллективное экологическое сознание, облако слов, экологический дискурс, частотный анализ, дистрибутивная семантика. 


\title{
Ethical foundations of human relations to natural objects
}

\author{
P. N. Vinogradov ${ }^{1}$, P. A. Yarkin ${ }^{1}$ \\ ${ }^{1}$ Herzen State Pedagogical University of Russia, \\ 48 Moika River Emb., Saint Petersburg 191186, Russia
}

\begin{abstract}
Authors:
Vinogradov Pavel N.

e-mail: palvin@mail.ru

ResearcherID : E-9964-2017

ORCID: 0000-0003-0012-7813

SPIN: 6143-3151

Yarkin Petr A.

e-mail: petr.yarkin@gmail.com

ResearcerID: D-7094-2017

ORCID: 0000-0001-6722-2474

SPIN: 9242-7352

Funding:

This research was funded by

Russian Foundation for Basic

Research (RFBR),

project no. 19-013-00835.

Copyright:

(C) The Authors (2019).

Published by Herzen State

Pedagogical University of Russia.
\end{abstract}

Abstract. In the process of interaction with natural objects, a person implements a certain pattern of behaviour. This activity is regulated by a system of perceptions and values, which the person realizes to varying degrees. The subject of the research is the value foundations of ethical choice, expressed in a linguistic description of environmental problems that people realize when interacting with natural objects. Students are invited to write environmental essays. The text explaining the choice reveals the features of the discourse employed. Distributive semantic methods were used for textual analysis. Such an approach allows us to construct a classification of the grounds for ethical environmental choice and to design educational materials corresponding to the students' characretistics. The article reveals one of the methodological techniques for the study of collective environmental consciousness, which is based on the analysis of texts generated by students. Texts of essays on a given topic are analysed in terms of the frequency of use of certain words. To test our assumptions, we analysed students' essays on the topic "What is acceptable in the relationship between people and nature?". An analysis of a word cloud is presented, with the help of which one can characterise the ecological discourse, and on its basis describe the content of environmental consciousness. This corpus of texts reflects the collective characteristics of environmental awareness and the social representations of students studying in various specialties. Here, by social representations, we understand a form of knowledge that arises from collective creativity and has a practical orientation. This, in turn, allows us to create a common reality for a social group. Analysis was performed in R version: 3.5.1 using the Quanteda package version: 1.4.3. Creating a script in the $\mathrm{R}$ language allows us to automate processing and repeat analysis on other textual corpora.

Keywords: collective ecological consciousness, word cloud, ecological discourse, frequency analysis, distributive semantics.

\section{Введение}

Экологические проблемы, стоящие перед человечеством, являются важнейшими в перечне противоречий, задающих конфликтность современной эпохи. Человече- ский фактор, являющийся важнейшим элементом такой конфликтности, связан с доминирующим типом экологического сознания. Исследование экологического сознания, как правило, производится методами, 
которые позволяют человеку давать социально желательные ответы. Целью нашей работы является описание дискурса, который используется учащимися в процессе осмысления экологических проблем и решения экологических задач, связанных с этическим выбором. Цель - обоснование и апробация такого метода, который построен на анализе проективных конструктов экологического сознания, выраженного в текстах. В работе мы используем определение В. И. Медведева и А. А. Алдашевой, которые, проанализировав взгляды представителей различных наук, приходят к следующей формулировке: «Экологическое сознание - это сформированная в виде понятийного аппарата система отношений человека к его связям с внешним миром, к возможностям и последствиям изменения этих связей в интересах человека или человечества, а также распространение существующих концепций и представлений, имеющих социальную природу, на явления и объекты природы и на их взаимные связи с человеком» (Медведев, Алдашева 2001, 6). Ключевыми пунктами в приведенном определении для нас являются: понятийная система, проявляющая специфику экологического сознания; отражение в ней связей и отношений человека с внешним природным миром, социальный характер присвоения человеком взглядов на эти понятия и их взаимоотношения. В основу исследуемого текстового материала положена концепция Т. М. Дридзе, автора семиосоциопсихологической парадигмы, дающей принципиально новые возможности изучения и понимания взаимообращенных процессов, происходящих между человеком и его информационной средой (Дридзе 1984). Слово-понятие как главная номинативная единица языка во многих случаях представляет собой некую отсылку к объекту или явлению как элементу реальной действительности, связующее звено между объектом или явлением и мыслью о нем, это делает слово центром субъектно-объектного бы- тия вещи. Исследователь языкового содержания экологического сознания О. С. Хряпченкова показала, что «...смыслообразующие и конструктивные особенности языка способны не просто обозначать и символизировать уже имеющиеся объекты и явления социальной реальности, но и производить соответствующие им концепты» (Хряпченкова 2013, 4). Содержание экологического сознания находит выражение в экологическом дискурсе, который понимается как совокупность текстов, в которых публично определены взаимоотношения человека и окружающей среды (Хряпченкова 2013). По нашему мнению, свободно композиционные тексты, создаваемые студентами, могут успешно использоваться не только как средство обучения, но и средство диагностики в области экологического образования (Александров, Воронцов 2015). Психологическая характеристика учебных текстов нашла свое отражение в исследовании П. Н. Виноградова и П. А. Яркина (2007; 2019), которое позволило выделить основные смысловые характеристики представления о природе и особенности естественнонаучных учебных текстов.

\section{Материалы и методы}

В данной работе анализируются тексты, которые были написаны студентами Института дефектологического образования и реабилитации РГПУ им. А. И. Герцена в рамках изучения дисциплины Психология. Задание заключалось в том, чтобы написать эссе на тему «Что может позволить себе человек в отношениях с природой?». Это задание было дано после лекции, на которой обсуждалась концепция нравственного развития Лоуренса Колберга. Помимо воспитательных задач, связанных с экологическим сознанием, это задание имело целью повторение материала лекции, наталкивало на активное преобразование знаний о нравственном развитии человека. Эссе выполнялось в рамках самостоятельной работы, результат высылался преподавателю по 
электронной почте. Специальный акцент на идеях морали и нравственности в задании не содержался.

\section{Результаты исследования \\ и их обсуждение}

Было получено 130 текстов объёмом от 444 до 1647 слов (медиана - 815 слов, среднее - 846,6). Анализ проводился в среде R version: 3.5.1 (R Core Team 2018) с использованием пакета Quanteda version: 1.4 .3 (Benoit K, Watanabe K, Wang Н и др., 2018). Создание скрипта на языке R позволяет автоматизировать обработку и повторять анализ на других корпусах текстов. На первом этапе слова приводились к нормальной форме (для существительных - именительный падеж, единственное число, для прилагательных - именительный падеж, единственное число мужского рода; для глаголов, причастий и деепричастий - глагол в инфинитиве). Эта операция проводилась автоматически с помощью морфологического анализатора Mystem (Segalovich I, 2003). Эта же программа использовалась для разметки частей речи, к каждому слову был добавлен идентификатор после знака подчеркивания (_s - существительное, _v глагол,_a - прилагательное,_adv - наречие). В сжатом виде наиболее частотные слова можно представить в виде облака слов, где размер шрифта отображает частоту встречаемости.

На рисунках 1, 2 и 3 приведены 50 наиболее частотных существительных, глаголов и прилагательных соответственно. Графический вариант эмпирического материала в виде визуального словесного облака позволяет выявить ядерное содержание экологического дискурса, те слова и категории, которые с большой вероятностью будут встречаться в любом тексте на эту тему. На рисунке явно прослеживается антропоцентрическая парадигма, когда человек находится в центре, а природа его окружает. Многие авторы склоняются к тому, что в рамках такой парадигмы сложно решить основные вопросы социоприродного взаимодействия (Дерябо, 1999). Однако тема морально-нравственных отношений человека и природы практически не проявляется.

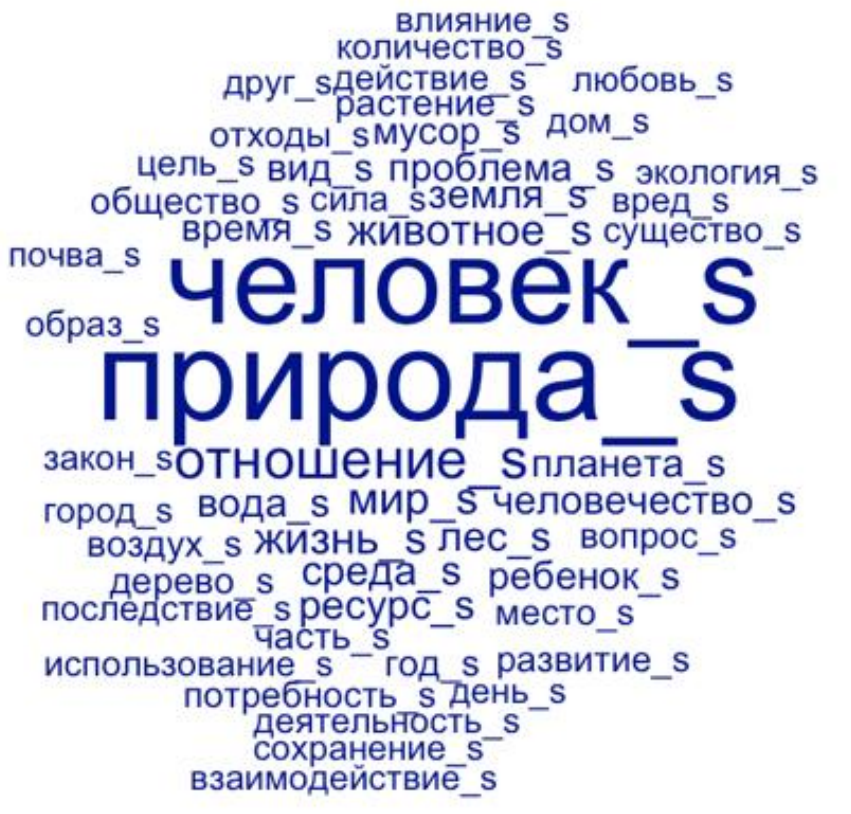

Рисунок 1 . Наиболее частотные существительные 


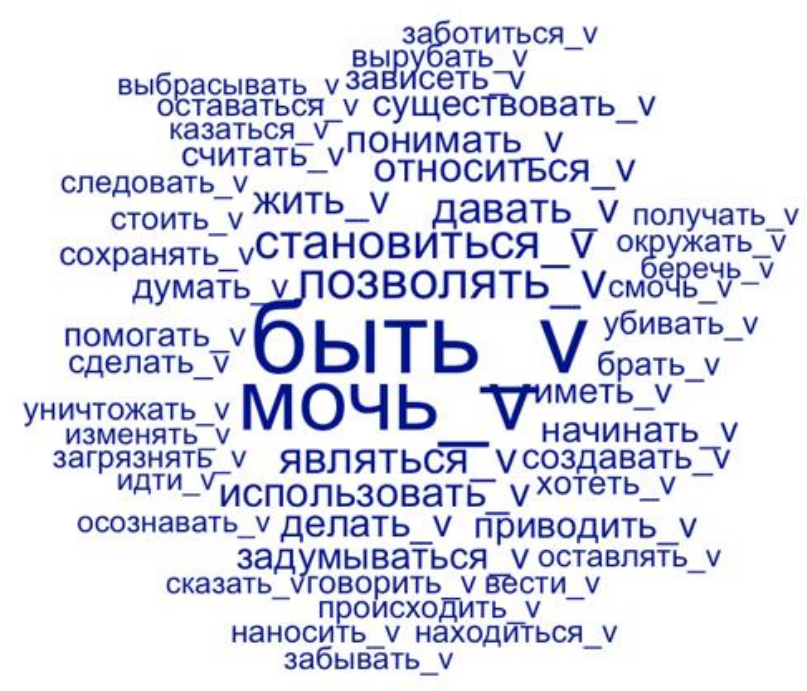

Рисунок 2. Наиболее частотные глаголы

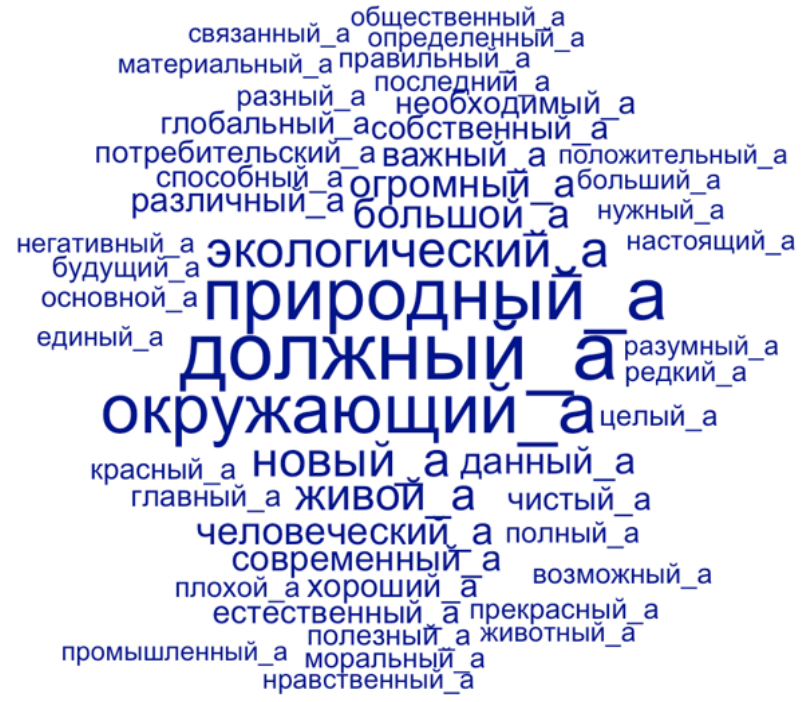

Рисунок 3. Наиболее частотные прилагательные

Во всём корпусе текстов было выделено 2818 существительных, 1614 глаголов, 1331 прилагательное и 496 наречий. В таблице 1 приведены частоты слов, которые были использованы как минимум в половине текстов. Среди 26 наиболее частотных слов мы видим слова, которые в первую очередь именуют природные слова и явления. Так, к группе природных объектов от- носится 13 категорий, к социальнопсихологическим категориям следует отнести 5 категорий: человек, человечество, общество, ребенок, отношение. Категории жизнь, образ, мир, среда, место и время общие категории. Среди категорий, относимых к характеристике кризисности отношений природы и общества, можно отнести только категории проблема и мусор. 
Таблица 1. Наиболее частотные слова

(указаны частоты и, в скобках, количество текстов с этим словом)

\begin{tabular}{|l|l|l|}
\hline \multicolumn{1}{|c|}{ Сушествительные } & \multicolumn{1}{|c|}{ Глаголы } & \multicolumn{1}{|c|}{ Прилагательные } \\
\hline природа 2769 (130) & мочь 694 (128) & природный 287 (106) \\
человек 2583 (130) & быть 847 (126) & должный 332 (102) \\
отношение 701 (123) & становиться 272 (110) & окружаюший 266 (99) \\
жизнь 360 (118) & позволять 309 (103) & новый 155 (71) \\
мир 373 (117) & являться 221 (93) & большой 111 (71) \\
животное 344 (110) & давать 204 (91) & огромный 104 (68) \\
земля 245 (107) & относиться 182 (88) & живой 134 (67) \\
среда 273 (98) & жить 180 (86) & экологический 167 (65) \\
лес 272 (98) & понимать 158 (86) & \\
ресурс 266 (96) & использовать 186(81) & \\
время 174 (94) & делать 160 (78) & \\
человечество 229 (91) & существовать 134 (75) & \\
планета 216 (88) & считать 110 (74) & \\
проблема 213 (87) & начинать 130 (72) & \\
вид 193 (87) & пметь 120 (68) & \\
вода 233 (86) & создавать 119 (68) & \\
часть 149 (85) & задумываться 142 (66) & \\
год 132 (79) & зависеть 104 (66) & \\
растение 145 (77) & хотеть 95 (65) & \\
ребенок 206 (75) & \\
мусор 175 (75) & \\
воздух 133 (75) & \\
место 119 (70) & \\
дерево 138 (68) & \\
образ 100 (66) & \\
общество 138 (65) & & \\
\hline
\end{tabular}

В перечне представленных глаголов присутствует 19 слов. Они включают мочь, быть, становиться, использовать, хотеть, позволять (последнее связано с формулировкой темы эссе) и характеризующими, в первую очередь, всевластие человека над объектами и явлениями природы. Появляются важные категории понимать, считать и задумываться, характеризующие мыслительную деятельность человека, но они находятся во второй части списка. И только в самом конце списка намек на подчиненный характер связи природы и человека, категория - зависеть.

При характеристике категорий, относящихся к группе прилагательных (8 слов), преобладают слова, описывающие природу и окружающий мир в целом. На этом фоне несколько выделяется характеристика должный, занимающая в списке второе ме- сто. Вместе с тем, оценочных категорий, отражающих не столько удивление и констатацию видимого, а направленных на соизмерение деятельности человека с нормами отношения к природным объектам, мы во главе списка не обнаружили.

В таблице 2 приведены частоты слов, связанных со словами мораль, нравственность и этика, а также оценочные слова хорошо и плохо. В списке интересующих нас категорий, относящихся к сфере этических отношений, мы обнаружили 17 примеров. Данные категории как бы направлены на активизацию нравственно-оценочной деятельности человека. Их задача - продемонстрировать глубину включенности размышлений и деятельности человека в структуру нравственно-экологического сознания. Полученные результаты демонстрируют сравнительно низкую частот- 
ность категорий, направленных на нравственную оценку фактов и явлений. На первое место выходят простейшие оценки, которые появляются в первые периоды жизни. Как правило, это характеризует синкретический уровень сознания, при котором все явления, вызывающие дискомфорт, тревогу оцениваются интегрально, как плохие. Все явления, вызывающие удоволь- ствие, воспринимаются как хорошие. Следует отметить, что и эти оценочные слова включены только в 30-50 \% исследуемых текстов. Категории нравственный и моральный появляются в студенческом лексиконе, но они носят низкочастотный характер и используются только в 17-18 \% текстов.

Таблица 2. Частоты ключевых слов

\begin{tabular}{|l|c|c|c|}
\hline \multicolumn{1}{|c|}{ Лемма } & $\begin{array}{c}\text { Частота } \\
\text { использования }\end{array}$ & $\begin{array}{c}\text { Ранг (по } \\
\text { частям } \\
\text { речи) }\end{array}$ & $\begin{array}{c}\text { Количество } \\
\text { текстов }\end{array}$ \\
\hline хороший_а & 67 & 15 & 50 \\
\hline хорошо_adv & 46 & 21 & 35 \\
\hline плохой_а & 43 & 30 & 35 \\
\hline нравственньй_а & 37 & 37 & 23 \\
\hline моральный_а & 42 & 33 & 22 \\
\hline плохо_adv & 25 & 38 & 20 \\
\hline нравственность_s & 23 & 228 & 13 \\
\hline мораль_s & 20 & 262 & 12 \\
\hline этика_s & 11 & 437 & 11 \\
\hline этический_а & 11 & 171 & 8 \\
\hline этически_аdv & 4 & 192 & 4 \\
\hline морально_аdv & 2 & 262 & 2 \\
\hline морально-нравственный_a & 1 & 784 & 1 \\
\hline моральность_s & 2 & 1218 & 1 \\
\hline морализм_s & 1 & 1618 & 1 \\
\hline этикет_s & 1 & 1618 & 1 \\
\hline этичность_s & 1618 & 1 \\
\hline
\end{tabular}

Дальнейшая обработка будет связана с сравнением частот используемых испытуемыми слов с тем, как эти слова употребляются в языке в целом, с какой частотой и в каких контекстах. Для этого может быть использован Национальный корпус русского языка и методики дистрибутивной семантики (Kutuzov, Kuzmenko 2017).

\section{Выводы}

1. Анализ экологического дискурса представленных эссе студентов позволяет выявить структуру их коллективного экологического сознания и содержательно охарактеризовать наиболее активно функционирующие компоненты группового экологического сознания.

2. Установлено доминирование антропоцентрического компонента экологического сознания, представленного противоречием природных категорий в группе существительных с одновременным преобладанием глаголов, выражающих ведущую активность человека. В дискурсе ограни- 
ченно представлены категории, выявляющие взаимодействие природных и социальных структур действительности.

3. Выявлено, что нравственный компонент экологического сознания представлен фрагментарно, он характеризуется низкой частотой использования этических категорий и ограниченностью субъектов - носителей. Нравственно-экологический компонент сознания функционирует на синкретическом уровне.

\section{Литература}

Александров, Е. П., Воронцова М. В. (2015) Учебный текст и текстовая деятельность в образовательном процессе. Современные наукоемкие технологии, № 6, с. 56-61.

Виноградов, П. Н., Яркин, П. А. (2007) Психологический анализ усвоения естственнонаучных текстов. В кн.: Тексты в образовательном пространстве современной высшей школы, Таганрог: Таганрогский государственный педагогический институт им. А. П. Чехова, c. 9-28.

Виноградов, П. Н., Яркин, П. А. (2019) Исследование коллективного экологического сознания посредством анализа композиционно свободных текстов Письма в Эмиссия.Оффлайн, №3, art. 2713. [Электронный pecypc]. URL: http://emissia.org/offline/2019/2713.htm (дата обращения 11.09.2019).

Дерябо, С. Д. (1999) Экологическая психология: диагностика экологического сознания, М.: МПСИ, $310 \mathrm{c.}$

Дридзе, Т. М. (1984) Текстовая деятельность в структуре социальной коммуникации. М.: Наука, 270 с.

Медведев, В. И., Алдашева, А. А. (2001) Экологическое сознание. М.: Логос, 384 с.

Хряпченкова, О. С. (2013) Язык как фактор экологического сознания общества : автореферат дис. ... канд. филос. наук. Нижний Новгород, 16 с.

Benoit, K., Watanabe, K., Wang H., Nulty, P., Obeng, A., Müller, S., Matsuo, A. (2018). “quanteda: An R package for the quantitative analysis of textual data." Journal of Open Source Software, vol. 3 (30), p. 774. doi: $10.21105 /$ joss.00774

Kutuzov, A., Kuzmenko, E. (2017) WebVectors: A Toolkit for Building Web Interfaces for Vector Semantic Models. In: Ignatov, D. et al. (eds.) Analysis of Images, Social Networks and Texts. AIST 2016. Communications in Computer and Information Science, vol. 661, pp. 155-161.

$R$ Core Team (2018). $R$ : A language and environment for statistical computing. $R$ Foundation for Statistical Computing, Vienna, Austria. [Электронный pecypc]. URL https://www.Rproject.org/ (дата обращения 11.09.2019).

Segalovich, I. (2003) A fast morphological algorithm with unknown word guessing induced by a dictionary for a web search engine. Proceedings of the MLMTA 2003. Las Vegas: CSREA Publ., pp. 273-280.

\section{References}

Aleksandrov, E. P., Vorontsova, M. V. (2015) Uchebnyi tekst i tekstovaya deyatel'nost' v obrazovatel'nom protsesse [Educational text and textual activity in the educational process]. Sovremennye naukoemkie tekhnologii [Modern high technology], no. 6, pp. 56-61 (In Russian)

Benoit, K., Watanabe, K., Wang H., Nulty, P., Obeng, A., Müller, S., Matsuo, A. (2018). "quanteda: An R package for the quantitative analysis of textual data." Journal of Open Source Software, vol. 3 (30), p. 774. doi: 10.21105/joss.00774 (In English) 
Deryabo, S. D. (1999) Ekologicheskaya psikhologiya: diagnostika ekologicheskogo soznaniya [Environmental Psychology: Diagnosis of Environmental Consciousness]. M.: MPSI Publ., 310 p. (In Russian)

Dridze, T. M. (1984) Tekstovaya deyatel'nost' v strukture sotsial'noi kommunikatsii [Textual activity in the structure of social communication]. M.: Nauka Publ., 270 p. (In Russian)

Khryapchenkova, O. S. (2013) Yazyk kak faktor ekologicheskogo soznaniya obshchestva [Language as a factor in the environmental consciousness of society. PhD thesis. Nizhnii Novgorod, $16 \mathrm{p}$. (In Russian)

Kutuzov, A., Kuzmenko, E. (2017) WebVectors: A Toolkit for Building Web Interfaces for Vector Semantic Models. In: Ignatov, D. et al. (eds.) Analysis of Images, Social Networks and Texts. AIST 2016. Communications in Computer and Information Science, vol. 661, pp. 155-161.

Medvedev, V. I., Aldasheva, A. A. (2001) Ekologicheskoe soznanie [Environmental awareness]. M.: Logos, 384 p. (In Russian)

$R$ Core Team (2018). R: A language and environment for statistical computing. $R$ Foundation for Statistical Computing, Vienna, Austria. [Online]. Available at: https://www.R-project.org/ (assessed 11.09.2019). (In English)

Segalovich, I. (2003) A fast morphological algorithm with unknown word guessing induced by a dictionary for a web search engine. Proceedings of the MLMTA 2003. Las Vegas: CSREA Publ., pp. 273-280. (In English)

Vinogradov, P. N., Yarkin, P. A. (2007) Psikhologicheskii analiz usvoeniya eststvennonauchnykh tekstov [Psychological analysis of the assimilation of natural science texts]. Teksty $v$ obrazovatel'nom prostranstve sovremennoi vysshei shkoly [Texts in the educational space of modern higher education], Taganrog: TGPI Publ., pp.9-28. (In Russian)

Vinogradov, P. N., Yarkin, P. A. (2019) Issledovanie kollektivnogo ekologicheskogo soznaniya posredstvom analiza kompozitsionno svobodnykh tekstov [The study of collective environmental consciousness through the analysis of compositionally free texts]. Pis'ma $v$ Emissiya.Offlain [The Emissia.Offline Letters], no. 3, art. 2713. [Online]. Available at: http://emissia.org/offline/2019/2713.htm (assessed 11.09.2019). (In Russian) 